\title{
Ellipsometric Expressions of Multilayered Substrate Coated with a Uniaxially Anisotropic Alignment Layer
}

\author{
Sang Youl $\mathrm{Kim}^{\dagger}$ \\ Department of Physics, Ajou University, 206 Worldcup-ro, Yeongtong-gu, Suwon 443-749, Korea
}

(Received August 5, 2013; Revised manuscript September 5, 2013; Accepted September 5, 2013)

\begin{abstract}
The effective reflection coefficients of an obliquely incident wave on a multi-layered substrate coated with a uniaxially anisotropic alignment layer are derived. The effective reflection coefficients as well as explicit ellipsometric expressions are provided as a function of film constants of multiple layers together with magnitude of anisotropy, direction of optic axis, and thickness of the alignment layer. It is expected that by adapting these expressions to the conventional modelling technique, the ordinary refractive index, the extra-ordinary refractive index, the azimuth angle and the tilt angle of the optic axis, and the thickness of the aligned surface can be determined simultaneously together with the thickness and volume fraction of each layer beneath the alignment layer.
\end{abstract}

Keywords: Reflection ellipsometry, Alignment layer, Uniaxial anisotropy, Tilt angle, Azimuth angle OCIS codes: (240.2130) Ellipsometry and polarimetry; (120.4630) Optical inspection; (240.0310) Thin films; (120.2040) Displays

\section{단축이방성 배향막이 코팅되어 있는 다층박막시료의 타원식 \\ 김상열 ${ }^{\dagger}$ \\ 아주대학교 물리학과 \\ (ㅇ) 443-749 경기도 수원시 영통구 월드컵로 206}

(2013년 8월 5일 받음, 2013년 9월 5일 수정본 받음, 2013년 9월 5일 게재 확정)

\begin{abstract}
다층박막이 있는 기층에 단축이방성 배향막이 코팅되어 있을 때 비스듬히 입사한 빛의 유효반사계수 표현들을 유도하였다. 유효반사계수들과 타원상수들을 다층박막의 미지상수들은 물론 단축이방성 배향막의 광학이방성의 크기와 광축의 방향 그리고 배향막의 두께로 표현하였다. 이를 바탕으로 배향막의 정상굴절률과 이상굴절률, 배향된 두께 그리고 광축의 방위각과 기울임각 을 다층박막의 두께나 조성비 등과 함께 타원법이 가지고 있는 높은 수준의 측정 정밀도를 유지하며 기존의 모델링 분석방법으 로 결정할 수 있도록 하였다.
\end{abstract}

Keywords: 반사타원법, 배향막, 단축이방성, 기울임각, 방위각

OCIS codes: (240.2130) Ellipsometry and polarimetry; (120.4630) Optical inspection; (240.0310) Thin films; (120.2040) Displays

\section{I. 연구 배경}

가장 대표적인 평판형 영상표시장치인 $\mathrm{LCD}$ (liquid crystal display)에서는 고화질의 LCD 패널을 효율적으로 생산하기 위해 잘 제어된 배향막의 형성이 필수적이며 $\mathrm{LCD}$ 산업현장 에서도 배향막 제작공정관리에 각별한 주의를 기울이고 있다. 배향막은 ITO 유리 등의 기층에 폴리이미드(polyimide, PI) 막을 형성하고 열경화를 거친 다음 러빙공정이나 자외선 조 사 공정 등을 거쳐 만들어진다. 배향막을 평가하는 방법으로

\footnotetext{
${ }^{\dagger}$ E-mail: sykim@ajou.ac.kr
}

Color versions of one or more of the figures in this paper are available online.
광학이방성이 큰 액정에 성공적으로 적용되어 온 통상적인 방법은 리타데이션(Retardation)으로 표시할 때 배향막의 광 학이방성이 0.1-0.3 nm 정도로 매우 작기 때문에 적당하지 않다. ${ }^{[1-4]}$ 광학이방성을 가진 물질을 평가하기 위해서는 대개 Mueller 편광법이나 일반화된 타원법(generalized ellipsometry) 을 사용한다. ${ }^{[5-8]}$ 이들 방법에서는 입사광의 편광상태를 바꾸 거나 반사 또는 투과광의 편광상태 측정방법을 바꾸거나 입 사각 또는 시료의 방위각을 변화시키며 측정한 타원상태 변 
화들을 종합적으로 분석하는데 배향막과 같이 리타데이션이 매우 작은 시료를 분석하기 위해서는 이방성 측정정밀도가 매우 높아야 하기 때문에 시료의 방위각을 회전시키는 방법 이 선호된다. ${ }^{[9]}$ 자기형성단분자(Self Assembled Monolayer) 의 극미소 광학이방성을 실시간으로 정밀하게 측정하는 방 법은 장비의 구조와 시료크기 제한 등으로 인하여 실용적이 지 못하며 ${ }^{[10]}$ 투과형 PCSA(polarizer-compensator-sample-analyzer) 타원계를 개선하여 배향막의 미세 이방성을 측정, 분석할 수 있도록 한 장비는 투과방식이므로 유리기층의 잔류 이방성 을 배향막 형성 이전에 별도로 측정하여 배경이방성으로 처 리해 주어야하는 번거로운 측면이 있다. ${ }^{[9]}$ 더구나 빛이 시료 면에 수직으로 입사하는 이 방법으로는 광학이방성의 크기 와 광축의 방위각만을 파악할 수 있을 뿐 정상굴절율과 이상 굴절률, 배향막의 두께 그리고 광축의 기울임각 분포를 분리 하여 결정할 수는 없다. 최근 시료면을 기울인 상태에서 시 료를 회전시키며 측정한 투과광의 편광상태 변화로부터 배 향막의 이방성 분포를 탐구한 연구도 있지만 투과광 측정으 로부터 기인한 한계는 극복하지 못하고 있다. ${ }^{[1]}$

한편 배향막을 광학이방성을 가지는 표면층과 광학적으로 등방성인 그 아래의 주층으로 나누고 반사 타원법을 적용하 여 표면층의 정상굴절률과 이상굴절률, 광축의 방위각과 기 울임각 그리고 표면층과 주층의 두께 들을 결정하려는 시도 가 Hirosawa에 의해 보고되었다. ${ }^{[12-15]}$ Hirosawa는 이방성 박 막이 있는 시료를 반사 타원법으로 분석하기 위해서 Berreman 의 $4 \times 4$ 행렬식을 이용하였는데 ${ }^{[16]}$ 이 식들은 유리기층위에 배향막이 있는 3 상계 구조에만 적용되는 표현으로 ITO 등 다층박막구조가 있는 기층과 같이 일반적인 배향막 시료의 분석에 적용하지 못하는 한계를 가지고 있다. 또한 Berreman 의 $4 \times 4$ 행렬식은 매우 복잡하여 사용하는데 불편하므로 상 대적으로 사용이 간편한 확장된(extended) Jones 행렬 방법이 많이 사용되는데 확장된 Jones 행렬 방법은 꼬인 네마틱(nematic) 액정과 같이 연속적으로 변하는 이방성 매질을 투과하는 빛 의 편광상태 변화를 해석하는데 주로 활용되어 왔다. ${ }^{[17-20]}$ 한 편 등방성 박막과 이방성 박막간의 경계면에서의 반사계수 와 투과계수는 잘 알려져 있지만 수식들이 상당히 복잡할 뿐 만 아니라 ${ }^{[21,22]}$ 이방성 박막이 다층박막위에 놓여있을 때 이 방성 박막과 등방성 다층박막 내에서의 다중반사를 고려한 유효반사계수는 보고되지 않고 있다.

본 연구에서는 반사 타원법에 널리 적용되고 있는 모델링 분석방법을 배향막의 정량분석에도 적용할 수 있도록 배향 막과 같은 단축이방성 박막이 등방성 다층박막 위에 있는 시 료에서 반사광의 편광상태변화와 타원상수 표현들을 제시한 다. 단축이방성 박막내 광축의 방향이 입사면에 수직하거나 입사면과 나란한 경우에는 반사타원상수 표현들이 잘 알려 져 있지만 ${ }^{[23]}$ 이들은 광축이 입사면과 이루는 각도가 일반각 일 경우에는 적용할 수 없으며 그나마도 3상계 구조에만 적 용되는 한계를 가지고 있다. 본 연구에서 제시되는 표현들은 광축의 방향에 대한 제약이 없을 뿐만이 아니라 기층에 등방 성 다층박막이 있는 시료에도 적용되는 일반식으로 활용성
이 넓다. 한편 타원상수를 얻기 위해 먼저 구한 유효반사계 수는 입사광의 입사각 의존성, 편광상태와 광축의 방향 및 시료의 방위각 의존성을 모두 고려하고 있으므로 편광의존 반사율 연구에도 유용하게 사용될 수 있을 것이다. 타원상수 표현들은 기존의 타원법에서 사용되는 소위 모델링 기법을 단축이방성 박막이 있는 시료에도 적용하여 배향막의 정상 굴절률과 이상굴절률, 배향막의 두께 그리고 광축의 방위각 과 기울임각 등을 그 아래의 다층박막의 두께나 조성비 등과 동시에 결정할 수 있게 하므로 다양한 기층위에 형성되어 있 는 배향막의 미세 광학이방성을 정밀하고도 간편하게 결정 할 수 있는 새로운 방법을 수립하는 기초가 될 것이다.

\section{II. 고유좌표계에서 단축이방성 박막이 기층위에 있는 3상계 시료의 유효반사계수}

좌표축 설정은 그림 1 과 같다. 빛은 $\mathrm{z}$ 축의 음의 방향에서 $\mathrm{z}$ 축의 양의 방향으로 진행하며 입사면은 $\mathrm{xz}$ 평면상에, 매질 과 시료의 경계면은 $\mathrm{xy}$ 평면상에 놓이도록 한다. 단축이방성 을 가지고 있는 박막내에서 광축이 $\mathrm{z}$ 축과 이루는 각도를 $\theta$, $\mathrm{xy}$ 평면상에 투영시켰을 때 광축이 $\mathrm{x}$ 축과 이루는 각도를 $\psi$ 로 표시한다. 단축이방성 박막내에서 $\mathrm{z}^{\prime}$ 축을 $\mathrm{z}$ 축과 일치시키 고 $\mathrm{x}^{\prime}, \mathrm{y}^{\prime}$ 축은 $\mathrm{x}, \mathrm{y}$ 축을 $\psi$ 만큼 회전시킨 새로운 $\mathrm{x}^{\prime}, \mathrm{y}^{\prime}, \mathrm{z}^{\prime}$ 좌표계를 설정한다. 이 좌표계에서는 전기장의 진동방향이 입사면과 나란한 $\mathrm{p}$ 파와 수직인 $\mathrm{s}$ 파가 각각 반사에서의 편광 고유상태가 되므로 이 좌표축을 고유(eigen) 좌표축이라 부 르기로 한다. 일반적으로 배향막은, 광축의 방향이 xy 평면 과 나란하지 않으므로 o-plate로 취급되지만 $\theta$ 가 $90^{\circ}$ 이면 광 축의 방향이 xy 평면과 나란한 a-plate가 된다.

다층박막이 있는 시료의 매질부터 시작하여 매질을 0 번, 제일 위에 있는 박막을 1 번, 그 다음 박막을 2 번과 같이 위 에서부터 번호를 매기기로 하자. 박막의 수가 k-1 이라면 기 층은 $\mathrm{k}$ 번이 되고 입사각을 $\phi_{0}, \mathrm{j}$ 번째 박막에서의 굴절각을 $\phi_{j}$

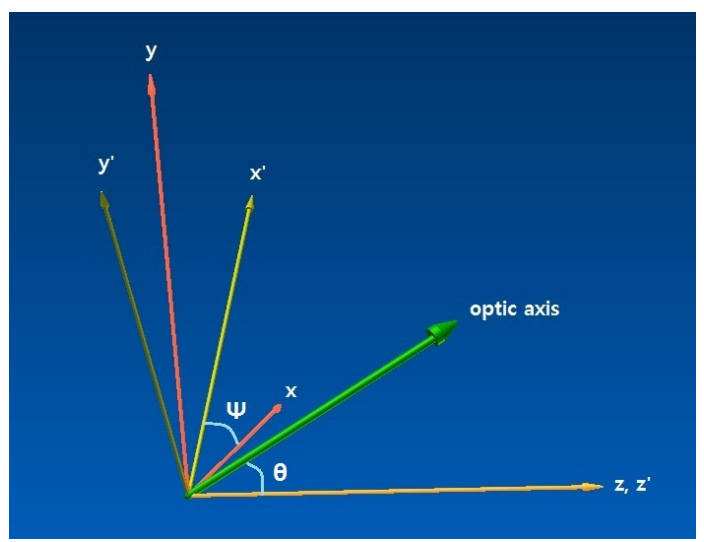

FIG. 1. A schematic figure showing the eigen axes (x'y'z'-axes) and the laboratory axes (xyz- axes) where the optic axis of the alignment layer makes an angle $\theta$ with $\mathrm{z}$-axis and its projection on xy plane makes an angle $\psi$ with $\mathrm{x}$-axis. 
그리고 $\mathrm{j}$ 번째 박막의 굴절률을 $n_{j}$ 와 같이 쓰기로 한다. 단축 이방성을 가지고 있는 배향막만이 있는 3상계 시료의 경우 이 배향막의 굴절률과 배향막내에서의 굴절각은 정상광선인 경우 $n_{1 o}$ 와 $\phi_{1 o}$, 이상광선일 경우 $n_{1 e}$ 와 $\phi_{1 e}$ 와 같이 각각 표 시하기로 한다. 좌표축방향으로 진동하는 전기장의 굴절률들 을 각각 $n_{1 x}{ }^{\prime}, n_{1 y}{ }^{\prime}, n_{1 z}{ }^{\prime}$ 라고 하면 이들은 광축이 $\mathrm{z}$ 축과 이루 는 각 $\theta$ 에 따라 각각 다음과 같이 된다.

$$
\begin{aligned}
& \frac{\sin ^{2} \theta}{n_{1 e}^{2}}+\frac{\cos ^{2} \theta}{n_{1 o}^{2}}=\frac{1}{n_{1 x}^{2}{ }^{\prime}} \\
& n_{1 y}{ }^{\prime}=n_{1 o} \\
& \frac{\cos ^{2} \theta}{n_{1 e}^{2}}+\frac{\sin ^{2} \theta}{n_{1 o}^{2}}=\frac{1}{n_{1 z}^{2}{ }^{\prime}}
\end{aligned}
$$

그림 2에서와 같은 고유좌표계에서 굴절률이 $n_{0}$ 인 등방 성 매질과 단축이방성 박막의 경계면에서의 Fresnel 반사계 수를 알아보자. 전기장의 진동방향이 입사면과 나란한 $\mathrm{p}$ 파는 이상광선이 되며 입사면과 수직인 $\mathrm{s}$ 파는 정상광선이 된다. 이들은 각각 반사의 고유편광상태이다. 즉 $\mathrm{p}$ 파가 입사하면 반사광은 $\mathrm{p}$ 파 성분만 존재하며 $\mathrm{s}$ 파가 입사하면 반사광 역시 $\mathrm{S}$ 파 성분만 존재하는데 이들의 Fresnel 반사계수 $r_{01 p p}, r_{01 s s}$ 는 다음과 같다. ${ }^{[23,24]}$

$$
\begin{aligned}
& r_{01 p p}=\frac{n_{1 x}{ }^{\prime} n_{1 z}{ }^{\prime} \cos \phi_{0}-n_{0}\left(n_{1 z}^{2}{ }^{\prime}-n_{0}^{2} \sin ^{2} \phi_{0}\right)^{1 / 2}}{n_{1 x}{ }^{\prime} n_{1 z}{ }^{\prime} \cos \phi_{0}+n_{0}\left(n_{1 z}^{2}{ }^{\prime}-n_{0}^{2} \sin ^{2} \phi_{0}\right)^{1 / 2}} \\
& r_{01 s s}=\frac{n_{0} \cos \phi_{0}-\left(n_{1 o}^{2}-n_{0}^{2} \sin ^{2} \phi_{0}\right)^{1 / 2}}{n_{0} \cos \phi_{0}+\left(n_{1 o}^{2}-n_{0}^{2} \sin ^{2} \phi_{0}\right)^{1 / 2}}
\end{aligned}
$$

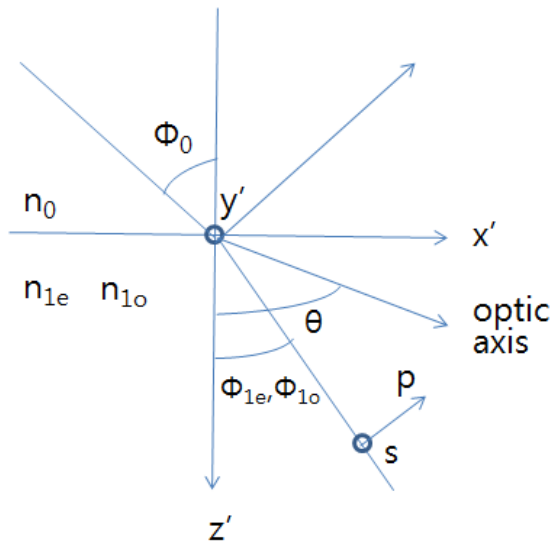

FIG. 2. Reflected wave and refracted wave at the interface between an isotropic ambient and a uniaxially anisotropic substrate, in the eigen axes (x'y'z'-axes).
마찬가지로 이 단축이방성 배향막과 그 위의 등방성 매질간 의 경계면에서 Fresnel 반사계수들은 각각 다음과 같다.

$$
\begin{aligned}
& r_{10 p p}=-r_{01 p p}=-\frac{n_{1 x}{ }^{\prime} n_{1 z}{ }^{\prime} \cos \phi_{0}-n_{0}\left(n_{1 z}^{2}{ }^{\prime}-n_{0}^{2} \sin ^{2} \phi_{0}\right)^{1 / 2}}{n_{1 x}{ }^{\prime} n_{1 z}{ }^{\prime} \cos \phi_{0}+n_{0}\left(n_{1 z}^{2}{ }^{\prime}-n_{0}^{2} \sin ^{2} \phi_{0}\right)^{1 / 2}} \\
& r_{10 s s}=-r_{01 s s}=-\frac{n_{0} \cos \phi_{0}-\left(n_{1 o}^{2}-n_{0}^{2} \sin ^{2} \phi_{0}\right)^{1 / 2}}{n_{0} \cos \phi_{0}+\left(n_{1 o}^{2}-n_{0}^{2} \sin ^{2} \phi_{0}\right)^{1 / 2}}
\end{aligned}
$$

이 단축 이방성 배향막 아래에 굴절률이 $n_{2}$ 인 등방성 박막 이 있을 때 이들의 경계면들에서 Fresnel 반사계수들 또한 아래식과 같다.

$$
\begin{aligned}
& r_{12 p p}=-\frac{n_{1 x}{ }^{\prime} n_{1 z}{ }^{\prime} \cos \phi_{2}-n_{2}\left(n_{1 z}^{2}{ }^{\prime}-n_{2}^{2} \sin ^{2} \phi_{2}\right)^{1 / 2}}{n_{1 x}{ }^{\prime} n_{1 z}{ }^{\prime} \cos \phi_{2}+n_{2}\left(n_{1 z}^{2}{ }^{\prime}-n_{2}^{2} \sin ^{2} \phi_{2}\right)^{1 / 2}} \\
& r_{12 s s}=-\frac{n_{2} \cos \phi_{2}-\left(n_{1 o}^{2}-n_{2}^{2} \sin ^{2} \phi_{2}\right)^{1 / 2}}{n_{2} \cos \phi_{2}+\left(n_{1 o}^{2}-n_{2}^{2} \sin ^{2} \phi_{2}\right)^{1 / 2}}
\end{aligned}
$$

여기서 등방성 매질간 Snell의 법칙에 따라 굴절각 $\phi_{2}$ 는 다 음과 같은 관계를 만족한다.

$$
n_{0} \sin \phi_{0}=n_{2} \sin \phi_{2}
$$

고유좌표계에서 그림 3 과 같이 단축이방성 박막이 등방성 기층위에 있는 3 상계 시료의 유효반사계수를 구하면 다음과 같다. 단축이방성 박막내에서 $\mathrm{p}$ 파의 박막복소계수 $\beta_{1 p}$ 와 $\mathrm{s}$ 파 의 복소박막계수 $\beta_{1 s}$ 를 각각 다음과 같이 정의하면

$$
\beta_{1 p}=\left(\frac{2 \pi d_{1}}{\lambda} \cdot \frac{n_{1 x}{ }^{\prime}}{n_{1 z}{ }^{\prime}}\right)\left(n_{1 z}^{2}{ }^{\prime}-n_{0}^{2} \sin ^{2} \phi_{0}\right)^{1 / 2}
$$

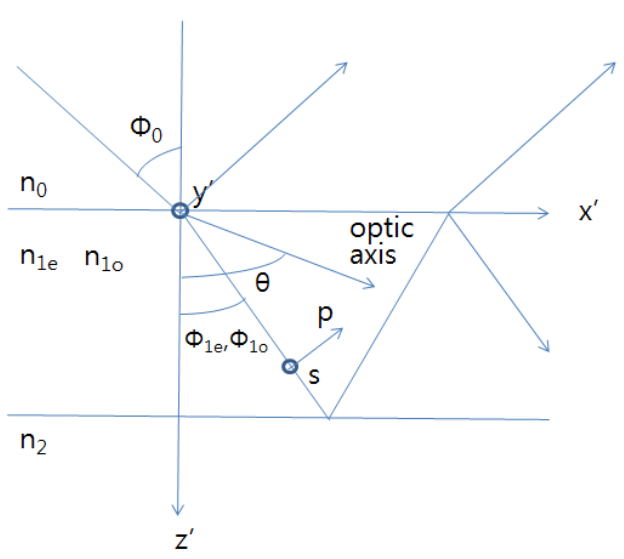

FIG. 3. Multiply reflected waves and multiply refracted waves by a 3-phase system in the eigen axes (x'y'z'-axes) where a uniaxially anisotropic film is coated on an isotropic substrate. 


$$
\beta_{1 s}=\frac{2 \pi d_{1}}{\lambda} \cdot\left(n_{1 o}^{2}-n_{0}^{2} \sin ^{2} \phi_{0}\right)^{1 / 2}
$$

고유좌표계에서 단축이방성 박막만이 있는 3상계 시료의 $\mathrm{p}$ 파의 유효반사계수 $\rho_{p}$ 와 $\mathrm{s}$ 파의 유효반사계수 $\rho_{s}$ 는 각각 다음 과 같다.

$$
\begin{gathered}
\rho_{p}=\frac{r_{01 p p}+r_{12 p p} e^{-2 i \beta_{1 p}}}{1+r_{01 p p} r_{12 p p} e^{-2 i \beta_{1 p}}} \\
\rho_{s}=\frac{r_{01 s s}+r_{12 s s} e^{-2 i \beta_{1 s}}}{1+r_{01 s s} r_{12 s s} e^{-2 i \beta_{1 s}}}
\end{gathered}
$$

\section{III. 실험실좌표계에서 단축이방성 박막이 다층박막기층 위에 있는 시료의 유효반사계수}

그림 4에서와 같이 실험실좌표계에서 다층박막이 있는 기 층위에 단축이방성 박막이 놓여 있는 시료가 반사광의 편광 상태에 미치는 작용을 나타내는 Jones 행렬을 $\overleftrightarrow{R}_{S}^{x y}$ 라 하면 이 Jones 행렬을 $(0,1)$ 경계면에서의 반사를 나타내는 행렬 인 $\overleftrightarrow{R}_{\text {surf }}$ 와 그 아래 경계면들에서의 반사를 나타내는 Jones 행렬들로 아래 식 (8) 및 식 (9)와 같이 쓸 수 있다. 아래의 Jones 행렬이나 Jones 벡터에 사용된 첨자들은 Azzam의 표 현방식을 따랐다. ${ }^{[23,25]}$ 예를 들어 반사행렬 $\overleftrightarrow{R}_{S}^{x y}$ 의 위첨자인 $\mathrm{xy}$ 는 실험실좌표계를 가리키며 아래첨자인 $\mathrm{S}$ 는 시료면을 가 리킨다.

$$
\left(\begin{array}{c}
E_{p}^{-} \\
E_{s}^{-}
\end{array}\right)=\overleftrightarrow{R}_{S}^{x y}\left(\begin{array}{c}
E_{p}^{+} \\
E_{s}^{+}
\end{array}\right)
$$

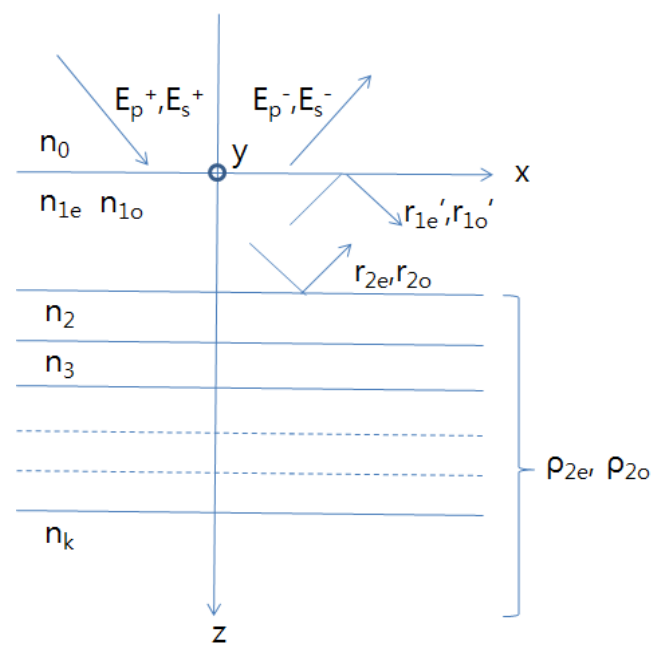

FIG. 4. A schematic figure showing the effective reflection by the multi-layered substrate coated with a uniaxially anisotropic film, in the laboratory axes (xyz-axes).

$$
\begin{aligned}
\overleftrightarrow{R}_{S}^{x y}= & \overleftrightarrow{R}_{\text {surf }}+\overleftrightarrow{T}_{i}^{\prime}\left[\stackrel{\leftrightarrow}{I}+\sum_{m=1}^{\infty}\left(\overleftrightarrow{P} \cdot \overleftrightarrow{R}^{e o} \cdot \overleftrightarrow{P} \cdot \overleftrightarrow{R}^{e o \prime}\right)^{m}\right] \\
& \cdot \overleftrightarrow{P} \cdot \overleftrightarrow{R}^{e o} \cdot \overleftrightarrow{P} \cdot \overleftrightarrow{T}_{i}
\end{aligned}
$$

여기서 식 (8)의 $E_{p}^{+}, E_{s}^{+}$는 각각 입사파의 전기장의 $\mathrm{p}$ 성분과 $\mathrm{s}$ 성분을 가리키며 $E_{p}^{-}$와 $E_{s}^{-}$는 각각 유효반사파의 전기장의 $\mathrm{p}$ 성분과 s성분을 가리킨다. 식 (9)의 각 Jones 행렬들을

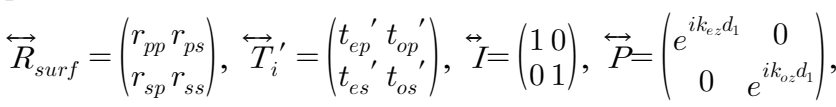
$\overleftrightarrow{R}^{e o}=\left(\begin{array}{cc}\rho_{2 e} & 0 \\ 0 & \rho_{2 o}\end{array}\right), \overleftrightarrow{R}^{e o \prime}=\left(\begin{array}{cc}r_{1 e}{ }^{\prime} & 0 \\ 0 & r_{1 o}^{\prime}\end{array}\right)$, 그리고 $\overleftrightarrow{T}_{i}=\left(\begin{array}{c}t_{p e} t_{s e} \\ t_{p o} t_{s o}\end{array}\right)$ 와 같 이 쓸 수 있는데 이 Jones 행렬의 각 성분들의 아래 첨자중 $\mathrm{p}$ 와 $\mathrm{s}$ 는 $\mathrm{p}$ 파 또는 $\mathrm{s}$ 파를 나타내며 $\mathrm{e}$ 나 $\mathrm{o}$ 는 이상광선 또는 정 상광선을 나타낸다. 이들 아래첨자 중 앞의 문자는 경계면으 로의 입사광을 나타내며 뒤의 문자는 경계면으로부터의 반 사광이나 투과광을 나타낸다. 그리고 ' 표시는 반대방향으로 진행하는 빛을 나타낸다. 예를 들어 $r_{p p}$ 는 매질에서 $\mathrm{z}$ 축의 양 의 방향으로 진행할 때 입사광이 $\mathrm{p}$ 파이고 반사광이 $\mathrm{p}$ 파일 경 우 매질과 단축이방성 배향막과의 경계면에서 Fresnel 반사 계수를 가리키며 $r_{p s}$ 는 같은 상황에서 입사광이 $\mathrm{p}$ 파이고 반 사광이 $\mathrm{s}$ 파일 경우 Fresnel 반사계수를 가리킨다. 따라서 $r_{p p}$ 는 식 (2a)의 $r_{01 p p}$ 와 같으며 $r_{s s}$ 는 식 (2b)의 $r_{01 s s}$ 와 같다. $t_{e p}{ }^{\prime}$ 은 단 축이방성 배향막과 매질과의 경계면에서 $\mathrm{z}$ 축의 음의 방향으 로 진행할 때 입사광이 이상광선이며 투과광이 $\mathrm{p}$ 파인 경우 Fresnel 투과계수를 나타내며 $t_{o p}{ }^{\prime}$ 은 마찬가지 상황에서 입사 광이 정상광선이며 투과광이 $\mathrm{p}$ 파인 경우 Fresnel 투과계수를 가리킨다. 참고로 등방성 매질과 이방성 매질간의 경계면에 서 반사계수들과 투과계수들의 구체적인 표현들은 $\mathrm{Yeh}^{[18]}$, $\mathrm{Lekner}^{[21]}$ 또는 $\mathrm{Ryu}^{[22]}$ 등에 의해 보고된 바 있다. 단축이방 성 박막을 통과하는 동안의 위상변화를 나타내는 행렬인 $\overleftrightarrow{P}$ 의 성분들을 식 (6a)와 (6b)의 박막복소변수를 사용하여 각각 다음과 같이 쓸 수 있다.

$$
\begin{aligned}
& e^{i k_{e z} d_{1}}=e^{i \beta_{1 p}} \\
& e^{i k_{o z} d_{1}}=e^{i \beta_{1 s}}
\end{aligned}
$$

한편 단축이방성 배향막과 매질간의 경계면에서의 이상광선 의 Fresnel 반사계수인 $r_{1 e}{ }^{\prime}$ 와 정상광선의 Fresnel 반사계수인 $r_{10}{ }^{\prime}$ 은 각각 식 (3a)와 식 (3b)의 $r_{10 p p}$ 와 $r_{10 s s}$ 와 같다.

마지막으로 단축이방성 배향막과 아래의 다층박막이 있는 기층과의 경계면에서의 유효반사계수들인 $\rho_{2 p}$ 와 $\rho_{2 s}$ 는 이상 광선과 정상광선 각각에 대해 기존의 다층박막구조의 유효 반사계수를 구하는 방법을 적용하여 다음과 같이 구한다. $\mathrm{x}^{\prime} \mathrm{y}^{\prime} \mathrm{z}$ 고유좌표계에서 $\mathrm{p}$ 파는 이상광선이고 $\mathrm{s}$ 파는 정상광선 이므로 $\rho_{2 e}$ 는 $\mathrm{p}$ 파의 유효반사계수인 $\rho_{2 p}$ 와 같고 $\rho_{2 o}$ 는 $\mathrm{s}$ 파의 


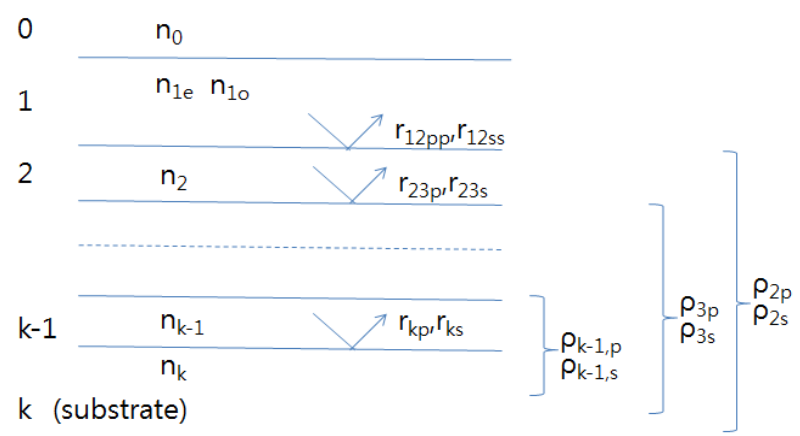

FIG. 5. A schematic figure showing the procedure of calculating ellipsometric expressions of the multi-layered substrate coated with a uniaxially anisotropic film.

유효반사계수인 $\rho_{2 s}$ 와 같다. 단축이방성 배향막 아래의 모든 박막은 등방성이므로 그림 5에서와 같이 기존의 다층박막에 적용되는 방법을 그대로 적용하여 $\rho_{2 p}$ 와 $\rho_{2 s}$ 의 표현을 X'y'z' 고유좌표계에서 다음과 같이 구한다. ${ }^{[26]}$ 즉

$$
\begin{aligned}
\rho_{k-1, x} & =\frac{r_{k-1, x}+r_{k x} e^{-2 i \beta_{k-1}}}{1+r_{k-1, x} r_{k x} e^{-2 i \beta_{k-1}}}(\mathrm{x}=\mathrm{p} \text { or } \mathrm{s}) \\
\rho_{j-1, x} & =\frac{r_{j-1, x}+\rho_{j x} e^{-2 i \beta_{j-1}}}{1+r_{j-1, x} \rho_{j x} e^{-2 i \beta_{j-1}}}(\mathrm{x}=\mathrm{p} \text { or } \mathrm{s}, k>j \geqq 4)
\end{aligned}
$$

라고 두면 유효반사계수 $\rho_{2 p}$ 와 $\rho_{2 s}$ 는 각각 다음과 같다.

$$
\begin{array}{r}
\rho_{2 p}=\frac{r_{12 p p}+\rho_{3 p} e^{-2 i \beta_{2}}}{1+r_{12 p p} \rho_{3 p} e^{-2 i \beta_{2}}} \\
\rho_{2 s}=\frac{r_{12 s s}+\rho_{3 s} e^{-2 i \beta_{2}}}{1+r_{12 s s} \rho_{3 s} e^{-2 i \beta_{2}}}
\end{array}
$$

여기서 $r_{j x}$ 는 $\mathrm{j}-1$ 번째 박막과 $\mathrm{j}$ 번째 박막의 경계면에서 $\mathrm{p}$ 파 $(x=p)$ 또는 $s$ 파 $(x=s)$ 의 Fresnel 반사계수를 가리키며 $j$ 번째 박 막의 박막복소계수와 굴절각은 각각 $\beta_{j}=\frac{2 \pi}{\lambda} n_{j} d_{j} \cos \phi_{j}$, $n_{0} \sin \phi_{0}=n_{j} \sin \phi_{j}(\mathrm{j}=3,4, \cdots)$ 와 같은 관계를 만족한다. 이 상과 같이 구한 반사계수, 투과계수 그리고 식 (10a)와 식 (10b) 의 위상표현들을 식 (9)에 대립하여 정리하면 시료의 작용을 나타내는 Jones 행렬인 $\overleftrightarrow{R}_{S}^{x y}$ 의 구체적인 표현을 구할 수 있 고 이를 형식적으로 다음과 같이 쓸 수 있다.

$$
\overleftrightarrow{R}_{S}^{x y}=\left(\begin{array}{ll}
T_{11} & T_{12} \\
T_{21} & T_{22}
\end{array}\right)
$$

\section{IV. 단축이방성이 작을 때 유효반사계수의 근사적인 표현}

만약 단축이방성의 크기가 작다면, 즉 $\left|n_{1 e}-n_{1 o}\right| \ll\left(n_{1 e}+n_{1 o}\right) / 2$ 가 성립한다면 $k_{e z} \approx k_{o z}$ 으로 근사할 수 있고 $\overleftrightarrow{R}_{s u r f}$ 와 $\overleftrightarrow{T}_{i}^{\prime}, \overleftrightarrow{T}_{i}$ 를 다음과 같이 근사식으로 대치시킬 수 있다. ${ }^{[18,22]}$

$$
\begin{aligned}
& \overleftrightarrow{R}_{\text {surf }} \cong \overleftrightarrow{R}(-\psi) \cdot\left(\begin{array}{cc}
r_{01 p p} & 0 \\
0 & r_{01 s s}
\end{array}\right) \cdot \overleftrightarrow{R}(\psi) \equiv \overleftrightarrow{R}(-\psi) \cdot \overleftrightarrow{R}_{01}^{x^{\prime} y^{\prime}} \cdot \overleftrightarrow{R}(\psi) \\
& \overleftrightarrow{T}_{i}^{\prime} \cong \overleftrightarrow{R}(-\psi) \cdot\left(\begin{array}{cc}
t_{10 p p} & 0 \\
0 & t_{10 s s}
\end{array}\right) \equiv \overleftrightarrow{R}(-\psi) \cdot \overleftrightarrow{T}_{10}^{x^{\prime} y^{\prime}} \\
& \overleftrightarrow{T}_{i} \cong\left(\begin{array}{cc}
t_{01 p p} & 0 \\
0 & t_{01 s s}
\end{array}\right) \cdot \overleftrightarrow{R}(\psi) \equiv \overleftrightarrow{T}_{01}^{x^{\prime} y^{\prime}} \cdot \overleftrightarrow{R}(\psi)
\end{aligned}
$$

여기서 $\overleftrightarrow{R}(\psi)=\left(\begin{array}{cc}\cos \psi & \sin \psi \\ -\sin \psi & \cos \psi\end{array}\right)$ 는 회전행렬이며 $t_{01 p p}$ 와 $t_{01 s s}$ 는 각각 매질과 단축이방성 박막간의 경계면에서 $\mathrm{p}$ 파와 $\mathrm{s}$ 파 의 Fresnel 투과계수를 가리키며 $t_{10 p p}$ 와 $t_{10 s s}$ 는 각각 단축이 방성 박막과 매질간의 경계면에서 $\mathrm{p}$ 파와 $\mathrm{s}$ 파의 Fresnel 투과 계수로써 구체적인 표현은 아래식과 같다.

$$
\begin{aligned}
& t_{01 p p}=\frac{2 n_{0} n_{1 z}{ }^{\prime} \cos \phi_{0}}{n_{1 x}{ }^{\prime} n_{1 z}{ }^{\prime} \cos \phi_{0}+n_{0}\left(n_{1 z}^{2}-n_{0}^{2} \sin ^{2} \phi_{0}\right)^{1 / 2}} \\
& t_{01 s s}=\frac{2 n_{0} \cos \phi_{0}}{n_{0} \cos \phi_{0}+\left(n_{1 o}^{2}-n_{0}^{2} \sin ^{2} \phi_{0}\right)^{1 / 2}} \\
& t_{10 p p}=\frac{2 n_{1 x}{ }^{\prime}\left(n_{1 z}^{2}{ }^{\prime}-n_{0}^{2} \sin ^{2} \phi_{0}\right)^{1 / 2}}{n_{1 x}{ }^{\prime} n_{1 z}{ }^{\prime} \cos \phi_{0}+n_{0}\left(n_{1 z}^{2}{ }^{\prime}-n_{0}^{2} \sin ^{2} \phi_{0}\right)^{1 / 2}} \\
& t_{10 s s}=\frac{2\left(n_{1 o}^{2}-n_{0}^{2} \sin ^{2} \phi_{0}\right)^{1 / 2}}{n_{0} \cos \phi_{0}+\left(n_{1 o}^{2}-n_{0}^{2} \sin ^{2} \phi_{0}\right)^{1 / 2}}
\end{aligned}
$$

여기에서 $n_{1 x}{ }^{\prime}$ 과 $n_{1 z}{ }^{\prime}$ 는 식 (1a), 식 (1c)에서 주어진 바와 같 다. 이들을 (9)에 대입하면 다음과 같은 표현을 얻는다.

$$
\overleftrightarrow{R}_{S}^{x y} \cong \overleftrightarrow{R}(-\psi) \cdot \overleftrightarrow{R}_{S}^{x^{\prime} y^{\prime}} \cdot \overleftrightarrow{R}(\psi)
$$

단

$$
\begin{aligned}
\overleftrightarrow{R}_{S}^{x^{\prime} y^{\prime}}= & \overleftrightarrow{R}_{01}^{x^{\prime} y^{\prime}}+\overleftrightarrow{T}_{10}^{x^{\prime} y^{\prime}}\left[\stackrel{\leftrightarrow}{I}+\sum_{m=1}^{\infty}\left\{\overleftrightarrow{P} \cdot\left(\begin{array}{cc}
\rho_{2 p} & 0 \\
0 & \rho_{2 s}
\end{array}\right) \cdot \overleftrightarrow{P} \cdot \overleftrightarrow{R}_{10}^{x^{\prime} y^{\prime}}\right\}^{m}\right] \\
& \cdot \overleftrightarrow{P} \cdot\left(\begin{array}{cc}
\rho_{2 p} & 0 \\
0 & \rho_{2 s}
\end{array}\right) \cdot \overleftrightarrow{P} \cdot \overleftrightarrow{T}_{01}^{x^{\prime} y^{\prime}}
\end{aligned}
$$

이다. 식 (17b)에서 $\overleftrightarrow{R}_{01}^{x^{\prime} y^{\prime}}$ 과 $\overleftrightarrow{R}_{10}^{x^{\prime} y^{\prime}}$ 는 각각 식 (2)와 식 (3)의 
반사계수들을 사용하여 식 (18a)와 식 (18b)와 같이 쓰여지 며 나머지 행렬들은 비대각선 성분이 0 인 Jones 행렬들이므 로 $\overleftrightarrow{R}_{S}^{x^{\prime} y^{\prime}}$ 은 비대각선 성분이 0 인 대각행렬이다. 이 행렬의 대 각선성분들은 각각 반사 고유편광상태인 $\mathrm{p}$ 파와 $\mathrm{s}$ 파의 고유 치이며 반사에 따른 $\mathrm{p}$ 파의 고유치와 $\mathrm{s}$ 파의 고유치를 각각 $\rho_{1 p}, \rho_{1 s}$ 라고 두면 $\overleftrightarrow{R}_{S}^{x^{\prime} y^{\prime}}$ 은 식 (19)와 같이 쓸 수 있다.

$$
\begin{aligned}
& \overleftrightarrow{R}_{01}^{x^{\prime} y^{\prime}}=\left(\begin{array}{cc}
r_{01 p p} & 0 \\
0 & r_{01 s s}
\end{array}\right), \\
& \overleftrightarrow{R}_{10}^{x^{\prime} y^{\prime}}=\left(\begin{array}{cc}
r_{10 p p} & 0 \\
0 & r_{10 s s}
\end{array}\right), \\
& \overleftrightarrow{R}_{S}^{x^{\prime} y^{\prime}}=\left(\begin{array}{cc}
\rho_{1 p} & 0 \\
0 & \rho_{1 s}
\end{array}\right)
\end{aligned}
$$

단

$$
\begin{array}{r}
\rho_{1 p}=\frac{r_{01 p p}+\rho_{2 p} e^{-2 i \beta_{1 p}}}{1+r_{01 p p} \rho_{2 p} e^{-2 i \beta_{1 p}}} \\
\rho_{1 s}=\frac{r_{01 s s}+\rho_{2 s} e^{-2 i \beta_{1 s}}}{1+r_{01 s s} \rho_{2 s} e^{-2 i \beta_{1 s}}}
\end{array}
$$

마지막으로 식 (19)를 식 (17a)에 대입하여 실험실좌표계에 서 시료의 작용을 나타내는 반사행렬인 $\overleftrightarrow{R}_{S}^{x y}$ 을 $\rho_{1 p}$ 와 $\rho_{1 s}$ 그 리고 시료의 방위각인 $\psi$ 의 함수로 다음과 같이 쓸 수 있다.

$$
\overleftrightarrow{R}_{S}^{x y}=\left(\begin{array}{l}
T_{11} T_{12} \\
T_{21} T_{22}
\end{array}\right)=\left(\begin{array}{ll}
\rho_{1 p} \cos ^{2} \psi+\rho_{1 s} \sin ^{2} \psi & \left(\rho_{1 s}-\rho_{1 p}\right) \sin \psi \cos \psi \\
\left(\rho_{1 s}-\rho_{1 p}\right) \sin \psi \cos \psi & \rho_{1 p} \sin ^{2} \psi+\rho_{1 s} \cos ^{2} \psi
\end{array}\right)
$$

\section{PSA(Polarizer-sample-analyzer) 구조의 타원계를 사용한 단축이방성 박막 시료의 분석}

앞절에서 구한 유효반사계수는 반사광을 이용한 단축이방 성 박막연구에 유용하게 사용될 수 있다. 한 예로써 리타데 이션이 매우 작은 배향막의 이방성 분포 결정에 적합한 반사 타원법에 이 표현들을 다음과 같이 적용할 수 있다. 회전검 광자 방식으로 구동하는 PSA 구조의 타원계에서(그림 6) 각 편광소자와 시료를 지난 후 빛의 편광상태는 다음과 같이 표 현된다.

$$
\vec{E}_{A O}^{t e}=\overleftrightarrow{T}_{A}^{t e} \cdot \overleftrightarrow{R}(A) \cdot \overleftrightarrow{R}_{S}^{x y} \cdot \overleftrightarrow{R}(-P) \cdot \vec{E}_{P O}^{t e}
$$

여기서 $\overleftrightarrow{T}_{A}^{+e}$ 는 검광자의 투과행렬로써 $\overleftrightarrow{T}_{A}^{t e}=K_{A}\left(\begin{array}{ll}1 & 0 \\ 0 & 0\end{array}\right)$ 와 같다.

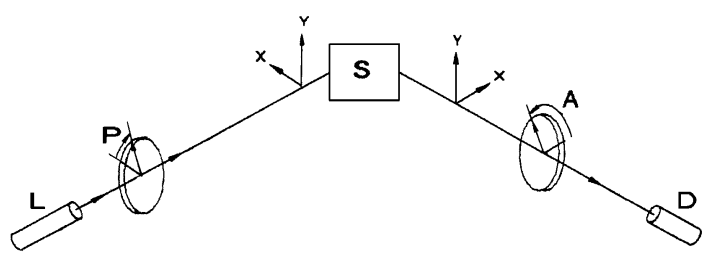

FIG. 6. The PSA ellipsometer arrangement with a linear polarizer $\mathrm{P}$, sample $\mathrm{S}$ and a linear analyzer $\mathrm{A}$. L and $\mathrm{D}$ are a light source and a linear photodetector array, respectively.

편광자를 통과한 빛의 전기장 벡터를 $\vec{E}_{P O}^{+e}=\left(\begin{array}{l}1 \\ 0\end{array}\right)$ 와 같이 정 규화한 Jones 벡터로 쓰고 식 (22)에 대입하여 검광자를 통 과한 전기장 벡터를 구하면

$$
\vec{E}_{A O}^{t e}=\left(\begin{array}{c}
E \\
0
\end{array}\right)
$$

와 같은 형태가 되는데 회전검광자 방식의 타원계에서는 이 전기장으로부터 빛의 세기를 구한 다음 회전하는 검광자의 각속도인 $\omega$ 의 조화함수로 다음과 같이 나타낸다.

$$
I_{D}=\mid E^{2}=I_{0}(1+\alpha \cos 2 \omega t+\beta \sin 2 \omega t)
$$

여기에서는 편광상태만을 관심의 대상으로 하므로 $K_{A}=1$ 으로 둔 다음 시료의 작용을 식 (13) 또는 식 (21)과 같이 쓸 때 식 (23)의 전기장은

$$
E=\cos A\left(T_{11} \cos P-T_{12} \sin P\right)+\sin A\left(T_{21} \cos P-T_{22} \sin P\right)
$$

와 같이 나타나므로 빛의 세기는 아래 식과 같이 유도된다.

$$
I=|E|^{2}=\zeta_{c c} \cos ^{2} A+\zeta_{s s} \sin ^{2} A+\zeta_{s c} \sin A \cos A
$$

단 식 (26)의 계수들은 다음과 같다.

$$
\begin{gathered}
\zeta_{c c}=\left|T_{11}\right|^{2} \cos ^{2} P+\left|T_{12}\right|^{2} \sin ^{2} P-\left(T_{11} T_{12}{ }^{*}+T_{11}{ }^{*} T_{12}\right) \sin P \cos P(27 \mathrm{a}) \\
\zeta_{s s}=\left|T_{21}\right|^{2} \cos ^{2} P+\left|T_{22}\right|^{2} \sin ^{2} P-\left(T_{21} T_{22}{ }^{*}+T_{21}{ }^{*} T_{22}\right) \sin P \cos P(27 \mathrm{~b}) \\
\zeta_{s c}=\begin{array}{c}
\left(T_{11} T_{21}{ }^{*}+T_{11} * T_{21}\right) \cos ^{2} P+\left(T_{12} T_{22}{ }^{*}+T_{12}{ }^{*} T_{22}\right) \sin ^{2} P \\
\quad\left(T_{11} T_{22}{ }^{*}+T_{11}{ }^{*} T_{22}+T_{12} T_{21}{ }^{*}+T_{12}{ }^{*} T_{21}\right) \sin P \cos P
\end{array}(27 \mathrm{c})
\end{gathered}
$$

식 (26)을 정리하여 식 (24)의 푸리에 계수들이 다음과 같이 나타남을 확인할 수 있다.

$$
I_{0}=\frac{\zeta_{c c}+\zeta_{s s}}{2}
$$




$$
\begin{gathered}
\alpha=\frac{\zeta_{c c}-\zeta_{s s}}{\zeta_{c c}+\zeta_{s s}} \\
\beta=\frac{\zeta_{s c}}{\zeta_{c c}+\zeta_{s s}}
\end{gathered}
$$

타원법에서 흔히 사용되는 모델링방법에서는 측정된 타원 상수 즉 식 (28b)와 식 (28c)의 푸리에계수에 미지 박막변수 (예를 들면 박막의 두께나 조성비 또는 굴절률 등)를 변화시 키며 계산된 타원상수를 최적맞춤하는 과정에서 미지 박막 변수를 결정한다. 예를 들어 위 식의 푸리에계수인 $\alpha, \beta$ 는 등방성다층박막이 있는 기층 위에 단축이방성 배향막이 코 팅되어 있는 시료의 구조와 광학물성에 의해 결정되는데 미 지 박막변수가 단축이방성 박막의 정상굴절률 $n_{o}$, 이상굴절률 $n_{e}$, 박막의 두께 $\mathrm{d}$, 그리고 광축의 방위각 $\psi$ 와 기울임각 $\theta$ 일 경우 이들을 미지변수로 하여 계산한 $\alpha, \beta$ 들을 측정한 값들에 최적맞춤함으로써 $n_{o}, n_{e}, \mathrm{~d}$ 그리고 $\psi, \theta$ 들을 결정하게 된다.

\section{VI. 요 약}

배향막과 같은 단축이방성 박막이 다층박막시료에 코팅되 어 있을 때 다층박막의 박막상수는 물론 이 배향막의 광학이 방성을 반영하여 유효반사계수들을 구하였다. 이 유효반사계 수를 바탕으로 회전검광자형 타원계에 적용되는 타원상수 표현들을 유도함으로써 기존의 모델링 분석방법으로 단축이 방성 배향막 아래에 있는 다층박막변수들을 포함하여 배향 막의 정상굴절률과 이상굴절률, 배향된 두께 그리고 광축의 방위각과 기울임각 등을 결정할 수 있도록 하였다. 배향막의 광학이방성이 작을 경우에 사용할 수 있는 비교적 간단한 표 현의 근사식을 제공함으로써 편광의존 반사율이나 타원법을 이용한 단축이방성 배향막 연구에 있어 일반연구자의 접근 성과 활용성을 대폭 향상시켰다.

\section{References}

1. C. Yu, J. Bae, C. M. Keum, and S. D. Lee, "Optical anisotropy of aligned pentacene molecules on a rubbed polymer corresponding to the electrical anisotropy," Current Applied Physics 10, 64-67 (2010).

2. C. Benecke, H. Seiberle, and M. Schadt, "Determination of director distribution in liquid crystal polymer-films by means of generalized anisotropic ellipsometry,” Jpn. J. Appl. Phys. 39, 525-531 (2000).

3. J. A. Ekhoff, M. J. Farrow, D. M. Walba, and K. L. Rowlen, "Molecular orientation of a model liquid crystal alignment layer," Talanta 60, 801-808 (2003).

4. M. Yamahara, M. Nakamura, N. Koide, and T. Sasaki, "Influence of rubbing conditions of polyimide alignment layer on optical anisotropy of immobilized liquid crystal film," Liquid Crystals 34, 381-387 (2007).
5. A. Martino, Y.-K. Kim, E. Garcia-Caurel, B. Laude, and B. Drevillon, "Optimized Mueller polarimeter with liquid crystals," Opt. Lett. 28, 616-618 (2003).

6. M. Schubert, R. Rheinlander, J. A. Woollam, B. Johs, and C. M. Herzinger, "Extension of rotating-analyzer ellipsometry to generalized ellipsometry: determination of the dielectric function tensor from uniaxial $\mathrm{TiO}_{2}$," J. Opt. Soc. Am. A 13, 875-883 (1996).

7. W. Xu, L. T. Wood, and T. D. Golding, "An ellipsometric method for the determination of the dielectric tensor of an optically uniaxial material suited for in-situ measurements," Thin Solid Films 384, 276-281 (2001).

8. G. E. Jellison, "Generalized ellipsometry for materials characterization," Thin Solid Films 450, 42-50 (2004).

9. K. H. Lyum, S. U. Park, S. M. Yang, H. K. Yoon, and S. Y. Kim, "Precise measurement of ultra small retardation of LCD alignment layer using improved transmission ellipsometry," Korean J. Opt. Photon. 24, 77-85 (2013).

10. G. Fang, J. Maclennan, and N. Clark, "High extinction polarimeter for the precision measurement of the in-plane optical anisotropy of molecular monolayers," Langmuir 26, 11686-11689 (2010).

11. K. H. Lyum, H. K. Yoon, S. J. Kim, and S. Y. Kim, "Study on ultra-small optical anisotropy profile of LCD alignment layer by using transmission ellipsometry," in Proc. the 6th International Conference on Spectroscopic Ellipsometry (Kyoto Research Park, 2013), p. 102.

12. I. Hirosawa, "Method of characterizating rubbed polyimide film for liquid crystal display devices using reflection ellipsometry," Jpn. J. Appl. Phys. 35, 5873-5875 (1996).

13. I. Hirosawa and N. Sasaki, "Influence of annealing on molecular orientation of rubbed polyimide film observed by reflection ellipsometry," Jpn. J. Appl. Phys. 36, 6953-6956 (1997).

14. I. Hirosawa, H. Miyairi, T. Matsushita, and S. Satio, "The relation between pretilt angle of liquid crystal and optical anisotropy of alignment film," Molecular Crystals and Liquid Crystals Science and Technology. Section A. Molecular Crystals and Liquid Crystals 368, 565-571 (2001).

15. S. Itoh and I. Hirosawa, "Observation of an optical anisotropy of rubbed polyimide film on actual LCD panel," Molecular Crystals and Liquid Crystals Science and Technology. Section A. Molecular Crystals and Liquid Crystals 367, 745-752 (2001).

16. D. W. Berreman, "Optics in stratified and anisotropic media: 4x4-matrix formalism,” J. Opt. Soc. Am. 62, 502-510 (1972).

17. A. Lien, "Extended Jones matrix representation for the twisted nematic liquid-crystal display at oblique incidence," Appl. Phys. Lett. 57, 2767-2969 (1990).

18. C. Gu and P. Yeh, "Extended Jones matrix method and its application in the analysis of compensator for liquid crystal displays," Displays 20, 237-257 (1999).

19. J. W. Ryu and S. Y. Kim, "Analysis of effective optic axis and equivalent retardation of composite optically anisotropic 
film by using transmission ellipsometry," Korean J. Opt. Photon. 20, 288-293 (2009).

20. J. W. Ryu, S. Y. Kim, and Y. K. Kim, "Determination of the optic axis distribution of a hybridly aligned discotic material for wide-view films," J. Korean Phys. Soc. 57, 233-239 (2010).

21. J. Lekner, "Reflection and refraction by uniaxial crystals," J. Phys.:Condens. Matter 3, 6121-6133 (1991).

22. J. W. Ryu, Ph. D. Thesis, Ajou University, Suwon (2010).
23. R. M. A. Azzam and N. M. Bashara, Ellipsometry and Polarized Light (North-Holland, Amsterdam, 1987), Chapter 3.

24. R. H. W. Graves, "Determination of the optical constants of anisotropic crystals," J. Opt. Soc. Am. 59, 1225-1227 (1969).

25. S. Y. Kim, Ellipsometry (Ajou University Press, Gyeonggi, Korea, 2000), Chapter 3-4.

26. O. S. Heaven, Optical Properties of Thin Films (Dover Publication, Inc., 1955). 